\title{
Producción de hidrógeno a partir de bio-oil sintético mediante steam-iron en lecho fijo
}

\author{
Jorge Plou, Paúl Durán, Javier Herguido, José Ángel Peña \\ Grupo de Catálisis, Separaciones Moleculares e Ingeniería de Reactores (CREG) \\ Instituto de Investigación en Ingeniería de Aragón (I3A). \\ Universidad de Zaragoza, Mariano Esquillor s/n, 50018, Zaragoza, Spain. \\ Tel.+34-976762707, Fax +34-976762043, e-mail: jplou@unizar.es
}

\begin{abstract}
Intensificación de los métodos de producción y purificación de hidrógeno a partir de bio-oil sintético utilizando el proceso steam-iron. El tradicional óxido metálico sometido a ciclos redox se complementa con un catalizador que favorece la descomposición de los compuestos orgánicos que constituyen el bio-oil.
\end{abstract}

\section{Introducción}

Hoy en día han aparecido nuevos retos en el sector de la energía debido al agotamiento de los combustibles fósiles. Uno de ellos es la búsqueda de una alternativa a esos combustibles fósiles que sea capaz de disminuir su actual explotación, o suponer su completa substitución a largo plazo. La más prometedora es el hidrógeno como vector de energía, que junto con la tecnología de las pilas de combustible, constituye una alternativa muy eficiente $y$ que no emite ningún tipo de contaminante. No obstante, el hidrógeno sólo puede ser considerado como una buena opción si la materia prima de la que procede y la fuente de energía con la que se produce son renovables. Un buen ejemplo lo constituye la producción a partir de biocombustibles, biomasa, bio-oil o biogás mediante procesos termoquímicos.

El trabajo está enfocado en el uso de bio-oil para la producción de hidrógeno a partir de un proceso llamado steam-iron (SIP) (Messerschmidt 1910). Aunque en el proceso SIP original sólo se utiliza óxido de hierro como reactivo principal, en este estudio se ha incluido el uso de catalizador para favorecer la descomposición del bio-oil. Se ha utilizado una mezcla sintética de tres compuestos orgánicos emulando la composición de un bio-oil real (producto líquido de la pirolisis rápida de biomasa).

El procedo SIP se compone de dos etapas REDOX. En primer lugar, la reducción de un óxido de hierro hasta su estado de oxidación mínimo mediante el paso de una corriente de combustible, como puede ser el hidrógeno, biogás o bio-oil vaporizado. En segundo lugar la oxidación con vapor de agua del hierro previamente reducido, generando hidrógeno de altísima pureza.

Los experimentos que han demostrado que es posible llevar a cabo este proceso se han realizado entre 600 y $800{ }^{\circ} \mathrm{C}$ en un reactor de lecho fijo. El sólido es una mezcla mecánica de óxido de hierro dopado con otros componentes minoritarios (Plou et al. 2014) y aluminato de níquel con exceso de níquel como catalizador. El bio-oil sintético es una mezcla de metanol, ácido acético e hidroxiacetona en proporciones análogas a aquellas encontradas en un bio-oil tipo (Bertero et al. 2012; Oasmaa and Meier 2005).

\section{Resultados}

Los resultados muestran que es posible reducir el sólido con la mezcla sintética propuesta a las temperaturas de trabajo utilizadas. El catalizador es también capaz de convertir completamente los reactivos en una mezcla de gases que tienen la suficiente capacidad reductora como para transformar el óxido de hierro en hierro metálico.

Como se observa en la Figura 1, el hecho de que en los primeros 20 min haya una cantidad menor de hidrógeno que en el resto del experimento es debido a su consumo en la reducción del sólido. A su vez, el flujo de $\mathrm{CO}_{2}$ sigue una trayectoria vinculada a la producción y oxidación del CO a lo largo del tiempo y su interacción con los distintos grados de oxidación del óxido de hierro.

En la siguiente etapa de oxidación con vapor de agua $\left(\sim 500{ }^{\circ} \mathrm{C}\right)$, el hidrógeno es producido con una concentración de $\mathrm{CO}_{2}$ muy baja ( 3\%), debido a la gasificación del carbono que se ha acumulado en la etapa previa de reducción. No se ha detectado CO en las condiciones de operación utilizadas. Como las pilas de combustible se envenenan con el monóxido de carbono pero no con el dióxido de 
carbono, la corriente de salida está ya totalmente adecuada para conectarse sin necesidad de una purificación extra. Tras 10 ciclos de reducciónoxidación se ha observado que el sólido ha perdido el $30 \%$ de su capacidad para generar hidrógeno y parece estar muy próximo a su comportamiento estable (Figura 2).

\section{REFERENCIAS}

[1]. BERTERO, M., PUENTE, G. de la and SEDRAN, U. Fuels from bio-oils: Bio-oil production from different residual sources, characterization and thermal conditioning. Fuel. 2012, 95, 263-271. Available from: doi:10.1016/j.fuel.2011.08.041.
[2]. MESSERSCHMITT, A. Process of producing hydrogen. U.S., Patent No. 465,686 ed. 1910.

[3]. OASMAA, A. and MEIER, D. Norms and standards for fast pyrolysis liquids: 1 . Round robin test. Journal of Analytical and Applied Pyrolysis. 2005, 73(2), 323334. Available from: doi:10.1016/j.jaap.2005.03.003.

[4]. PLOU, J., DURÁN, P., HERGUIDO, J. and PEÑA, J.A. Purified hydrogen from synthetic biogas by joint methane dry reforming and steam-iron process: Behaviour of metallic oxides and coke formation. Fuel. 2014, 118, 100-106. Available from: doi: http://dx.doi.org/10.1016/j.fuel.2013.10.069

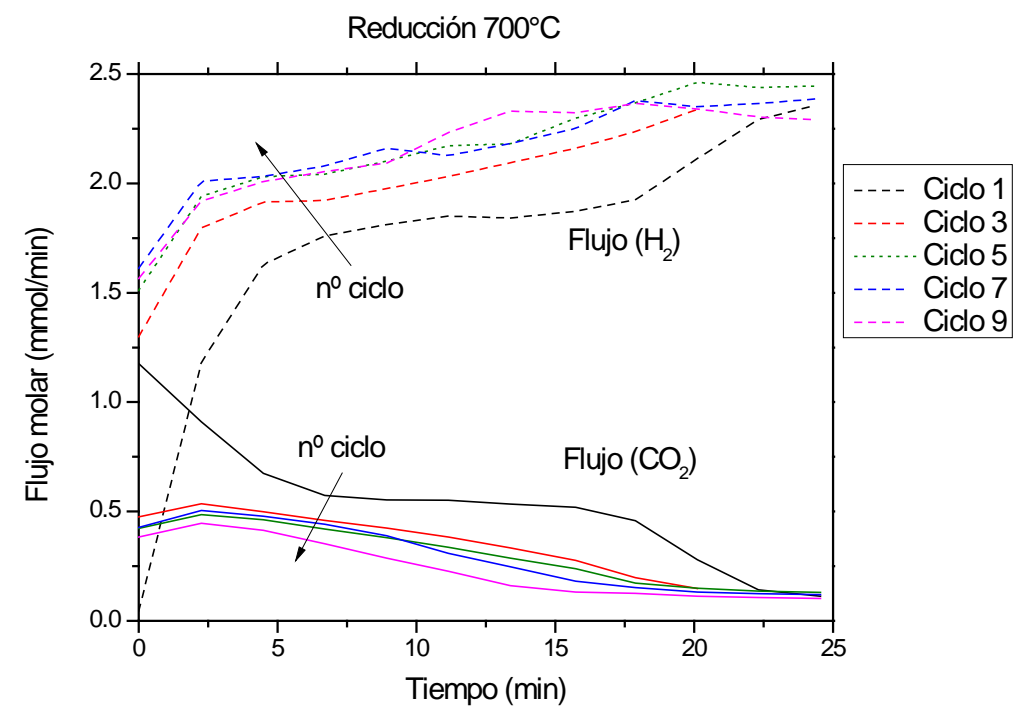

Figura 1. Etapa de reducción de los ciclos 1, 3, 5, 7 y 9 a $700^{\circ} \mathrm{C}$ de una mezcla $47.5 \%$ de ácido acético, $37.5 \%$ de hidroxiacetona y $15 \%$ de metanol.

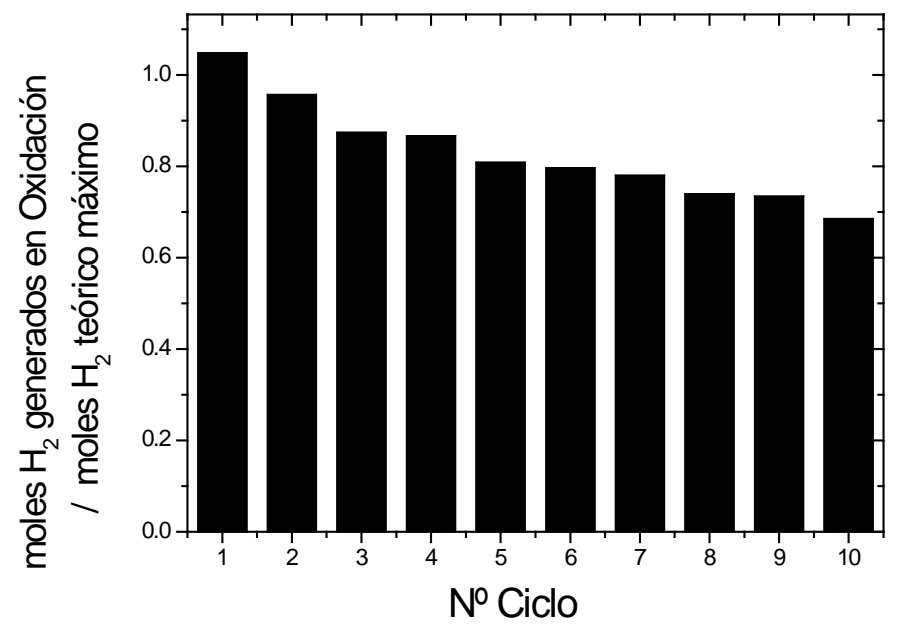

Figura 2. Cantidad de hidrógeno producido en la etapa de oxidación respecto al teórico máximo 